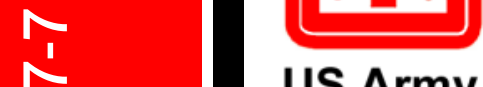

US Army Corps

of Engineers ${ }_{\circledast}$

Engineer Research and

Development Center

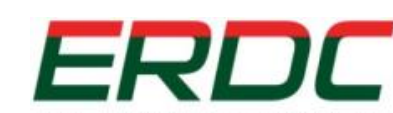

INNOVATIVE SOLUTIONS for a safer, better world

\title{
A Creep Model for High-Density Snow
}

Robert B. Haehnel

April 2017

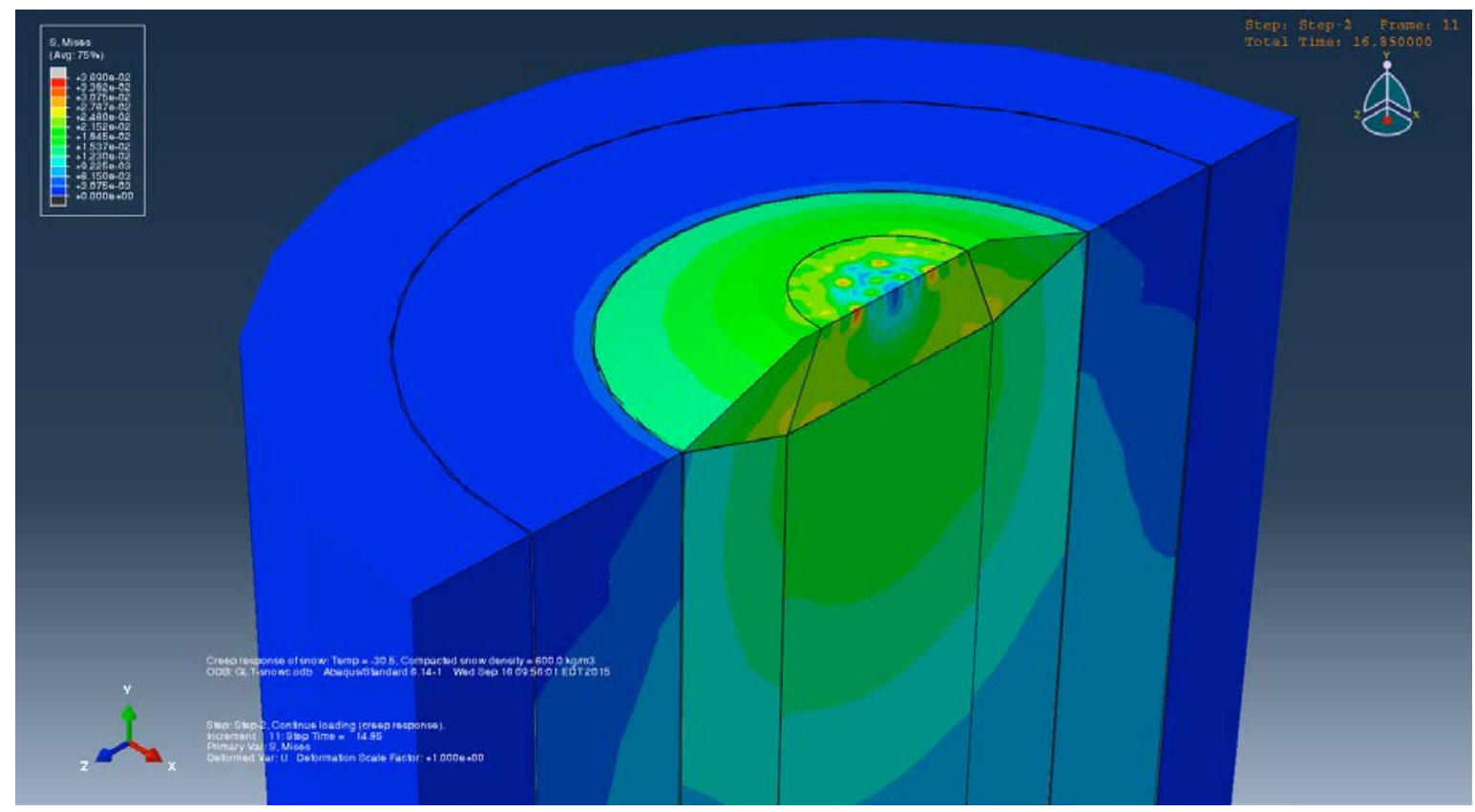


The U.S. Army Engineer Research and Development Center (ERDC) solves the nation's toughest engineering and environmental challenges. ERDC develops innovative solutions in civil and military engineering, geospatial sciences, water resources, and environmental sciences for the Army, the Department of Defense, civilian agencies, and our nation's public good. Find out more at www.erdc.usace.army.mil.

To search for other technical reports published by ERDC, visit the ERDC online library at http://acwc.sdp.sirsi.net/client/default. 


\title{
A Creep Model for High-Density Snow
}

\author{
Robert B. Haehnel \\ U.S. Army Engineer Research and Development Center (ERDC) \\ Cold Regions Research and Engineering Laboratory (CRREL) \\ 72 Lyme Road \\ Hanover, NH 03755-1290
}

Final Report

Approved for public release; distribution is unlimited.
Prepared for Smithsonian Astrophysical Observatory 60 Garden Street Cambridge, MA 02138
Under Project SAO-GLT-16-01, “Greenland Telescope Snow Foundation Performance and Construction"




\section{Abstract}

This effort modifies Mellor and Smith's creep model for dense snow to conform to the more general creep power law form (Glen's creep law for ice is a special case of this power law). The present study used this general form as the basis for developing two creep models: one to describe the primary creep and another that models secondary creep response as a function of applied stress, snow density, and temperature. Available laboratory data helped to determine the parameters for these models. These models were recast into a form compatible with the ABAQUS finite element software to allow simulation of settlement of a snow foundation subjected to a long-term load.

The secondary creep model was validated against the observed settlement of a spread foundation on snow at Camp Century, Greenland. Though there were not suitable field data to validate the primary creep model, comparison of that model to results obtained for the secondary creep model demonstrate that the primary creep model behaved as expected. Additional work is necessary to merge the primary and secondary creep models and to further validate the primary creep response of the model presented here.

DISCLAIMER: The contents of this report are not to be used for advertising, publication, or promotional purposes. Citation of trade names does not constitute an official endorsement or approval of the use of such commercial products. All product names and trademarks cited are the property of their respective owners. The findings of this report are not to be construed as an official Department of the Army position unless so designated by other authorized documents. 


\section{Contents}

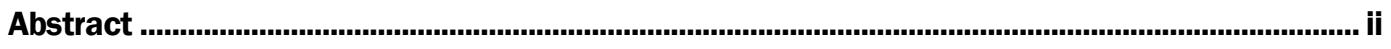

Figures and Tables......................................................................................................................

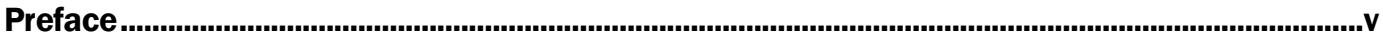

Unit Conversion Factors ................................................................................................................vi

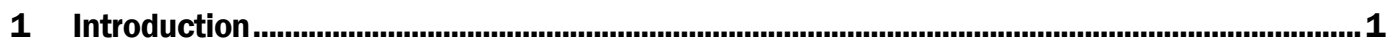

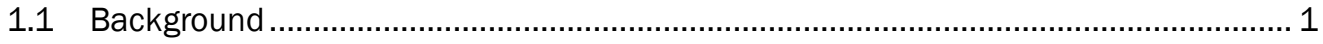

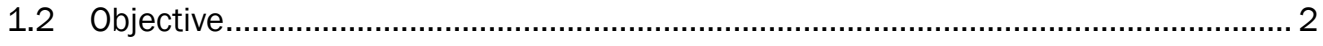

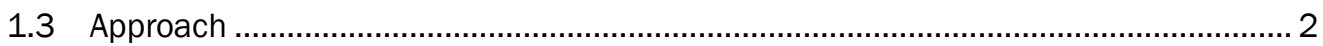

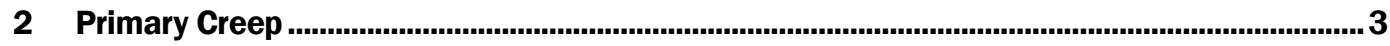

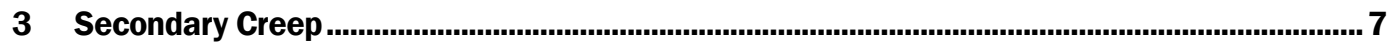

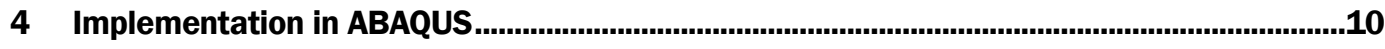

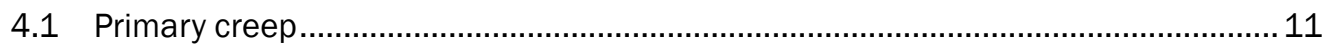

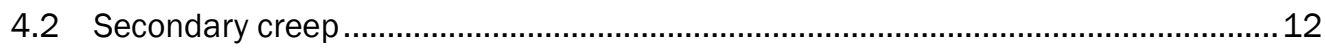

4.3 Including variation of density with depth..................................................... 13

5 Comparison of Primary and Secondary Creep Models......................................................16

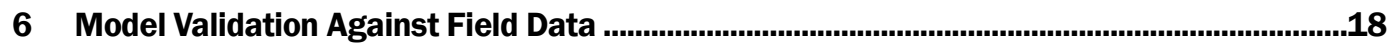

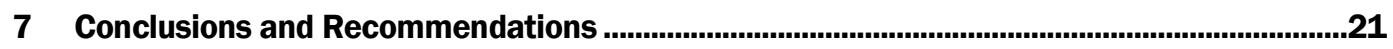

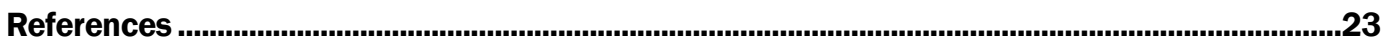

Appendix A: Density vs. Depth Material Model........................................................................24

Report Documentation Page 


\section{Figures and Tables}

\section{Figures}

1 A typical uniaxial strain curve for creep loading of a material.

2 Comparison of the primary creep model to experimental data for several temperatures. The first number in the legend is temperature $\left({ }^{\circ} \mathrm{C}\right)$, the second is snow density $\left(\mathrm{kg} / \mathrm{m}^{3}\right)$, and the third is the applied pressure $(\mathrm{kPa})$. (CSU is Chandel et al. 2007, and MMO is Meussen et al. 1999)

3 The symbols represent the temperature dependent creep data of Mellor and Smith (1966). The lines indicate the predicted value from Equation (2). The applied stress for all cases is $49 \mathrm{kPa}$ except where noted.

4 Comparison of data of secondary creep from Mellor and Smith (1966) (symbols) to Equation (7) (line) for the snow temperatures indicated and applied stress of $49 \mathrm{kPa}$. Note that for the temperature of $-20^{\circ} \mathrm{C}$, the ABAQUS constitutive model that follows was applied to a single element model and that the results between the finite element model and Equation (7) are indistinguishable. For all other lines in this figure except $-20^{\circ} \mathrm{C}$, only the model (Equation [7]) results are presented

5 Implemented in ABAQUS, a comparison of model results (Equation [3]) to the creep behavior of snow observed by Meussen et al. (1999). The simulated and measured data are for a snow temperature of $-20^{\circ} \mathrm{C}$ and a density of 450 $\mathrm{kg} / \mathrm{m}^{3}$. The applied load is $220 \mathrm{kPa}$.

6 Comparison of depth vs. density at Summit Station, Greenland (solid line), and linear approximation using 3 points

7 Comparison of axial strain predicted using Equation (3) (primary creep) as a function of snow temperature. For comparison, the figure also shows the axial strain predicted for the secondary creep relationship (dashed line) (Equation [6]). The snow density for all of these simulations is $550 \mathrm{~kg} / \mathrm{m}^{3}$. The applied stress is $15 \mathrm{kPa}$.

8 Comparison of model results to the data of Reed (1974). This is the same data obtained by Reed (1966) with the settlement rates adjusted to a snow density of $458 \mathrm{~kg} / \mathrm{m}^{3}$

9 The model domain used for simulating the load cases outlined in Reed (1966). The raft is not shown to allow viewing of the stress state of the snow immediately under the raft. The load case is quarter space for the $1.37 \mathrm{~m}$ raft loaded at 47.8 $\mathrm{kPa}$.

\section{Tables}

1 Activation energies determined by Mellor and Smith (1966)

2 Dependency of the elastic modulus on snow density extracted from data compiled in Shapiro et al. (1997). The data extracted follows more closely the data reported by Shapiro et al. (1997) that was acquired from low-strain-rate measurements, more closely akin to the foundation loading considered for the application of this model 


\section{Preface}

This study was conducted for the Smithsonian Astrophysical Observatory (SAO) under project SAO-GLT-16-01, "Greenland Telescope Snow Foundation Performance and Construction." The technical monitor was Timothy J. Norton, SAO.

The work was performed by the Terrestrial and Cryospheric Sciences Branch (CEERD-RRG), U.S. Army Engineer Research and Development Center, Cold Regions Research and Engineering Laboratory (ERDCCRREL). At the time of publication, CDRJ . D. Horne, USN (Ret.), was Chief, CEERD-RRG. The Deputy Director of ERDC-CRREL was Dr. Lance Hansen, and the Director was Dr. Robert E. Davis.

COL Bryan S. Green was Commander of ERDC, and Dr. David W. Pittman was the Director. 


\section{Unit Conversion Factors}

\begin{tabular}{|l|l|l|}
\hline Multiply & By & To Obtain \\
\hline calorie & 4.184 & joules \\
\hline feet & 0.3048 & meters \\
\hline inches & 0.0254 & meters \\
\hline pounds (force) per square foot & 47.88026 & pascals \\
\hline pounds (force) per square inch & 6.894757 & kilopascals \\
\hline
\end{tabular}




\section{Introduction}

\subsection{Background}

The Greenland Telescope (GLT) is a radio telescope that the Smithsonian Astrophysical Observatory proposes to install near Summit Station, Greenland, and that will be founded on a compacted snow surface. The deformation of snow under a constant load (creep deformation, or simply "creep") is dependent on both the density and temperature of the snow. Mellor and Smith (1966), Mellor (1969), Reed (1966, 1974), Kovacs (1967), Meussen et al. (1999) and Chandel et al. (2007) have previously studied this creep behavior. Creep is normally characterized as proceeding in three phases as depicted in Figure 1. During the initial phase, termed primary creep, the strain rate, $\dot{\varepsilon}$, varies with time, t, following roughly the trend $\dot{\varepsilon} \propto \mathrm{t}^{-\mathrm{p}}$ where $\mathrm{p}$ is a creep exponent. Following this initial period, secondary creep sets in, during which the strain rate is constant with time. In tertiary creep, the strain rate once again is time dependent following the trend of $\dot{\varepsilon} \propto \mathrm{tp}$, the exponent now positive. Based on experience at Camp Century and the Dye Sites in Greenland, I expect that the GLT foundation will experience secondary creep as the main mode of settlement throughout its lifespan. However, during dynamic operations (e.g., telescope pointing), I expect that the snow will experience some amount of primary creep as it receives a new increment of load during rotation of the eccentrically loaded dish. As such, this study considers models that capture both primary and secondary creep behaviors.

Figure 1. A typical uniaxial strain curve for creep loading of a material.

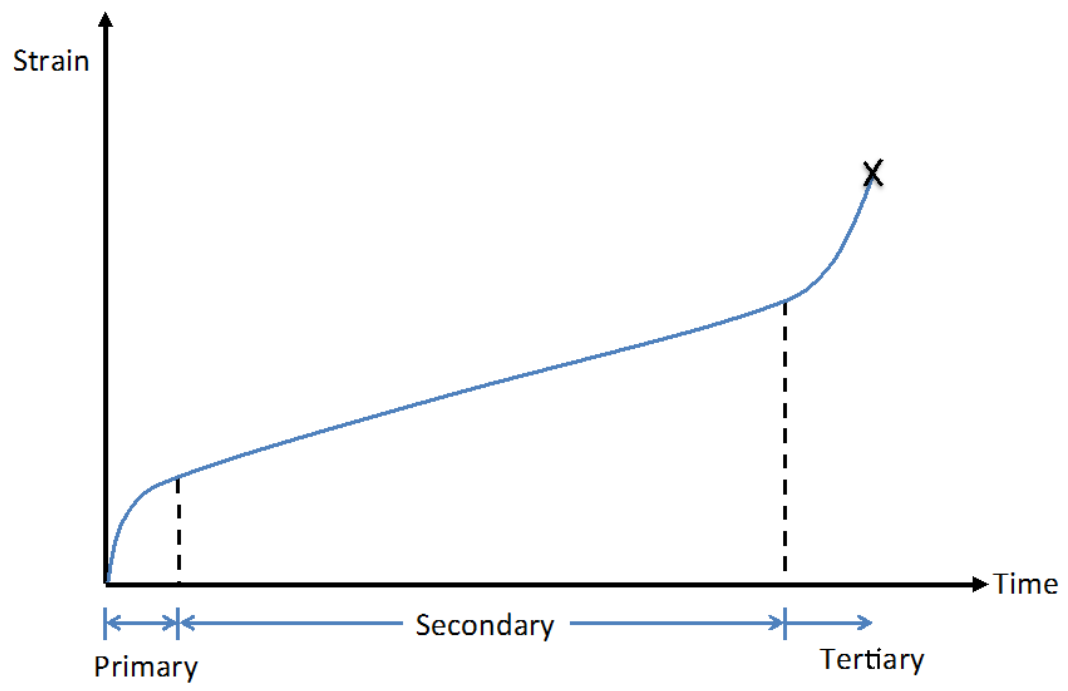




\subsection{Objective}

The objective of this effort was to develop a constitutive model that describes the creep response of dense snow ( $\rho=440-890 \mathrm{~kg} / \mathrm{m}^{3}$ ) for use in a finite element analysis to quantify long-term settlement of a structure placed on a snow foundation.

\subsection{Approach}

The primary creep model formulated here is based on the general creep power law. To model secondary creep, this effort generalized the model for snow proposed by Mellor and Smith (1966) so that creep could be computed as a function of applied load, snow temperature, and density (i.e., following the form of Glen's creep law for ice, Glen 1955). From this, I formulated a general model that is the basis for both the primary and secondary creep models, though the parameters needed for each differ. Available laboratory data helped to determine parameters for each model. The form of the models developed in this study are enough similar to the generalized creep model used in the ABAQUS finite element software that the ABAQUS creep model was used with minimal adaptation. Finally, I ran simulations of test cases using the finite element method to validate the models against available data. 


\section{Primary Creep}

Though primary creep in snow has not been extensively studied, a few published works have measured and developed models for primary creep of snow. Meussen et al. (1999) looked at the creep response of varyingdensity snow subjected to increasing applied loads at a constant temperature of $-20^{\circ} \mathrm{C}$. Chandel et al. (2007) provides data for a range of temperatures $\left(-3^{\circ} \mathrm{C}\right.$ to $\left.-9^{\circ} \mathrm{C}\right)$ while holding the load and density constant. Combining these data sets provides an opportunity to explore the variation in strain rate during initial creep loading for a wide range of density, $\rho$; applied stress, $\sigma$, and snow temperature, T. Assuming the strain rate during primary creep will have the following dependency $\dot{\varepsilon}=f(t, \rho, \sigma, T)$, I propose the use of the power form creep law (ABAQUS 2003):

$$
\dot{\varepsilon}=C_{\rho} C_{T} \sigma^{q} t^{p}
$$

I chose this form because of its compatibility with the standard ABAQUS creep model (discussed in more detail in the section "Implementation in ABAQUS") and its similarity to the secondary creep model proposed by Mellor and Smith (1966) for snow and Glen's creep law for ice (more commonly referred to as Glen's law).

Mellor and Smith (1966) proposed that, as with Glen's law for ice, the Arrhenius equation can also be used to quantify the temperature dependence of creep for snow:

$$
k=A \exp (-Q / R T)
$$

where

$$
\begin{aligned}
& \mathrm{k}=\text { rate constant for chemical reactions, } \\
& \mathrm{A}=\text { constant or proportionality, } \\
& \mathrm{Q}=\text { activation energy }(\mathrm{Cal} / \mathrm{mol}) \\
& \mathrm{R}=\text { the ideal gas constant }(1.985 \mathrm{Cal} / \mathrm{mol} \mathrm{K}), \text { and } \\
& \mathrm{T}=\text { absolute temperature in Kelvin. }
\end{aligned}
$$

Applying this, I assume that the temperature coefficient in Equation (1) has the form $\mathrm{C}_{\mathrm{T}}=\exp (-\mathrm{Q} / \mathrm{RT})$. Mellor and Smith (1966) also proposed $\mathrm{Q}=\mathrm{f}(\rho, \sigma)$ where $\rho$ is the snow density and $\sigma$ is the applied stress. Table 1 presents the values of Q determined by Mellor and Smith (1996) for snow. 
Here I make the assumption that $\mathrm{Q}=\mathrm{f}(\rho)$ only and that the variation in $\mathrm{Q}$ in the last two entries in Table 1 is not related to the applied stress but rather reflects measurement accuracy. I further assume that the average $\mathrm{Q}$ for $\rho=832 \mathrm{~kg} / \mathrm{m}^{3}$ is the correct value for that snow density. This adjustment to the approach of Mellor and Smith (1966) makes С a term that depends on snow temperature and density only. With this adjustment, I performed a curve fit to the $\mathrm{Q}$ data in Table 1 (the details of which are described in the next section) and determined empirically

$$
Q(\mathrm{kcal} / \mathrm{mol})=1208.2 \rho^{-0.704} ; \rho\left(\mathrm{kg} / \mathrm{m}^{3}\right) .
$$

I note, that applying an assumption $\mathrm{Q}=$ constant (e.g., average of all Q values in Table 1) degraded the model's ability to replicate measured data, providing a strong argument that $Q$ does vary with snow density as quantified in Equation (3).

Meussen et al. (1999) fit their strain data to an equation of the form $\varepsilon=\mathrm{Ct}^{\mathrm{n}}$. The strain rate is quite simply the time derivative of this expression: $\dot{\varepsilon}=\mathrm{nCt}^{\mathrm{n}-1}$. Therefore, I can use values of $\mathrm{C}$ and $\mathrm{n}$ determined by Meussen et al. (1999) to get an estimate for $\mathrm{C}_{\rho}$ and $\mathrm{p}=\mathrm{n}-1$ for Equation (1).

Table 1. Activation energies determined by Mellor and Smith (1966).

\begin{tabular}{|c|c|c|}
\hline Snow density, $\mathrm{kg} / \mathrm{m}^{3}$ & Applied uniaxial stress, $\mathrm{kPa}$ & Activation energy, kcal/mol \\
\hline 436 & 49 & 17.8 \\
\hline 531 & 49 & 14.0 \\
\hline 644 & 49 & 13.4 \\
\hline 832 & 98 & 10.7 \\
\hline 832 & 49 & 11.9 \\
\hline
\end{tabular}

I adjusted the fit used by Meussen et al. (1999) to more of a creep power law form $\left(\varepsilon=\mathrm{C}^{\prime} \mathrm{C} \sigma^{\mathrm{at}}{ }^{\mathrm{n}}\right)$ and recomputed the constant after accounting for the inclusion of stress and temperature. Furthermore, I determined that the exponent $q=1$ in Equation (1) describes the response of the data of Meussen et al. (1999). Because all of the data acquired by Meussen et al. (1999) was for snow at $-20^{\circ} \mathrm{C}$, I included data from Chandel et al. (2007) for snow at temperatures of $-3^{\circ} \mathrm{C}$ to $-9^{\circ} \mathrm{C}$ and obtained values of $\mathrm{C}^{\prime}$ and $\mathrm{n}$ for these data, also. This analysis reveals that $C^{\prime}$ varies with the snow density according to the empirical relationship $C^{\prime}=2.5 \times 10^{14} \exp (-0.046 \rho)$; 
$\mathrm{R}^{2}=0.98$. Furthermore, $\mathrm{n}$ varies only slightly with snow density and temperature; the average value is $n=0.526$ (standard deviation of 0.0834), and I assume that $\mathrm{n}=0.5$. The strain rate was determined by $\mathrm{p}=\mathrm{n}-1=$ -0.5 and $\mathrm{C}_{\rho}=\mathrm{nC}^{\prime}=1.25 \times 10^{14} \exp (-0.046 \rho)$, and thus the model for primary creep of snow is

$$
\begin{gathered}
\dot{\varepsilon}=C_{\rho} C_{T} \sigma t^{p} ; p=-0.5 ; C_{T}=\exp (-Q / R T) ; \\
C_{\rho}\left(\mathrm{s}^{-0.5} \mathrm{~Pa}^{-1}\right)=1.25 \times 10^{14} \exp (-0.046 \rho)
\end{gathered}
$$

where $\mathrm{Q}$ is determined from Equation (3). I provide a comparison of the measured strain to this model in Figure 2. The data are nondimensionalized in this plot to $\frac{\varepsilon}{{ }^{\prime} C_{T} \sigma}=t^{0.5}$ so that they can be plotted against the single line $\left(y=t^{0.5}\right)$ that represents the model response. Note that there is considerable scatter in the data and that the collapse is not as tight as I would hope when considering the fit to $\mathrm{C}^{\prime}$; and by extension $\mathrm{C}_{\rho}$, has such a high coefficient of determination $\left(R^{2}\right)$. Yet, clearly the exponent $p=-0.5$ is a reasonable representation of the trend in the data. The scatter in the data is likely a result of differences in the snow structure and the degree of interparticle sintering, which is the type of variability I expect in the natural environment; and I consider Equation (4) adequate for describing general trends of the primary creep response of snow. However, clearly further work is necessary to account for the sources of variability evident in Figure 2.

Note that this model is a little tenuous as the data I was able to locate extend from only $-3^{\circ} \mathrm{C}$ to $-20^{\circ} \mathrm{C}$. I would like to be able to extend the model to give us an estimate of the primary creep behavior around $-30^{\circ} \mathrm{C}$ (the expected temperature at depth for the GLT foundation). For now, I restricted the applicability of Equation (4) to $-3^{\circ} \mathrm{C} \geq \mathrm{T} \geq-50^{\circ} \mathrm{C}$ with the understanding that this model requires updating as further data become available. Even considering these limits, the model appears to perform adequately for snow densities between 440 and $890 \mathrm{~kg} / \mathrm{m}^{3}$, which encompass the range required for this study. 
Figure 2. Comparison of the primary creep model to experimental data for several temperatures. The first number in the legend is temperature $\left({ }^{\circ} \mathrm{C}\right)$, the second is snow density $\left(\mathrm{kg} / \mathrm{m}^{3}\right)$, and the third is the applied pressure ( $\mathrm{kPa}$ ). (CSU is Chandel et al. 2007, and MMO is Meussen et al. 1999).

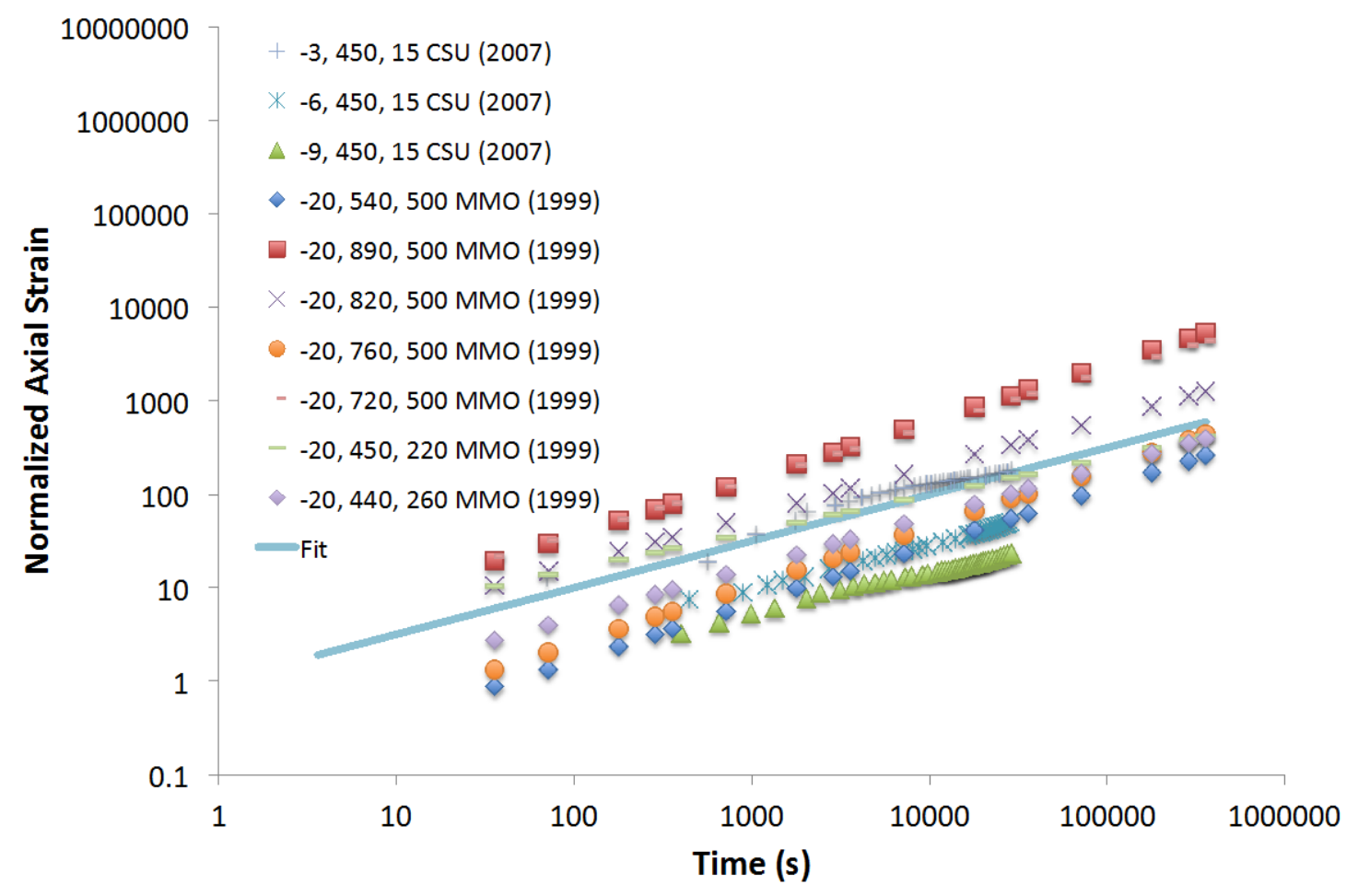




\section{Secondary Creep}

Mellor and Smith (1966) proposed the Arrhenius equation to quantify the secondary creep* behavior of the snow:

$$
\dot{\bar{\varepsilon}}=C_{1} e^{-Q / R T}
$$

Mellor and Smith (1966) empirically determined but did not publish the constant $\mathrm{C}_{1}$, units of $\mathrm{s}^{-1}$. This is a unique application of the Arrhenius equation; rather than explicitly account for the effect of applied stress as is done in the creep power law (Equation [1]), Mellor and Smith (1966) proposed a dependence of $\mathrm{Q}$ on applied stress as discussed above. I propose a modification to the approach of Mellor and Smith (1966) as follows. As with the primary creep model, I explicitly account for applied stress via $\mathrm{C}_{1}=\mathrm{K} \sigma$ to yield Glen's law with the exponent on stress, $\mathrm{q}=1$ :

$$
\dot{\bar{\varepsilon}}=K \sigma e^{-Q / R T}
$$

Further, I assume that K is a function of only snow density. Glen's law was developed to describe the creep response in ice; here, I assume that it can also be applied to describe the secondary creep response of dense snow.

To determine how the parameter $\mathrm{K}$ varies with snow density, I relied on the data of Mellor and Smith (1966) presented in Figure 3. The present study determined the parameter K from a least squares fit of Equation (6) by using the values of $\mathrm{Q}=\mathrm{f}(\rho)$ and $\sigma$ from Table 1 (noting that for $\rho=$ $832 \mathrm{~kg} / \mathrm{m}^{3}$, Q is the mean value for the two stress levels).

I observed that the data for K and Q associated with a snow density of $531 \mathrm{~kg} / \mathrm{m}^{3}$ had large residuals in comparison with the other cases. This had the effect of degrading the performance of the model when this study used fits obtained for K and $\mathrm{Q}=\mathrm{f}(\rho)$ such that the model did not faithfully follow any of the cases presented in Figure 3.

\footnotetext{
* Mellor and Smith (1966) note that it took strains of $2 \times 10^{-2}$ to $10^{-1}$ to transition to the secondary creep stage in their uniaxial compression tests.
} 
Figure 3. The symbols represent the temperature dependent creep data of Mellor and Smith (1966). The lines indicate the predicted value from Equation (2). The applied stress for all cases is $49 \mathrm{kPa}$ except where noted.

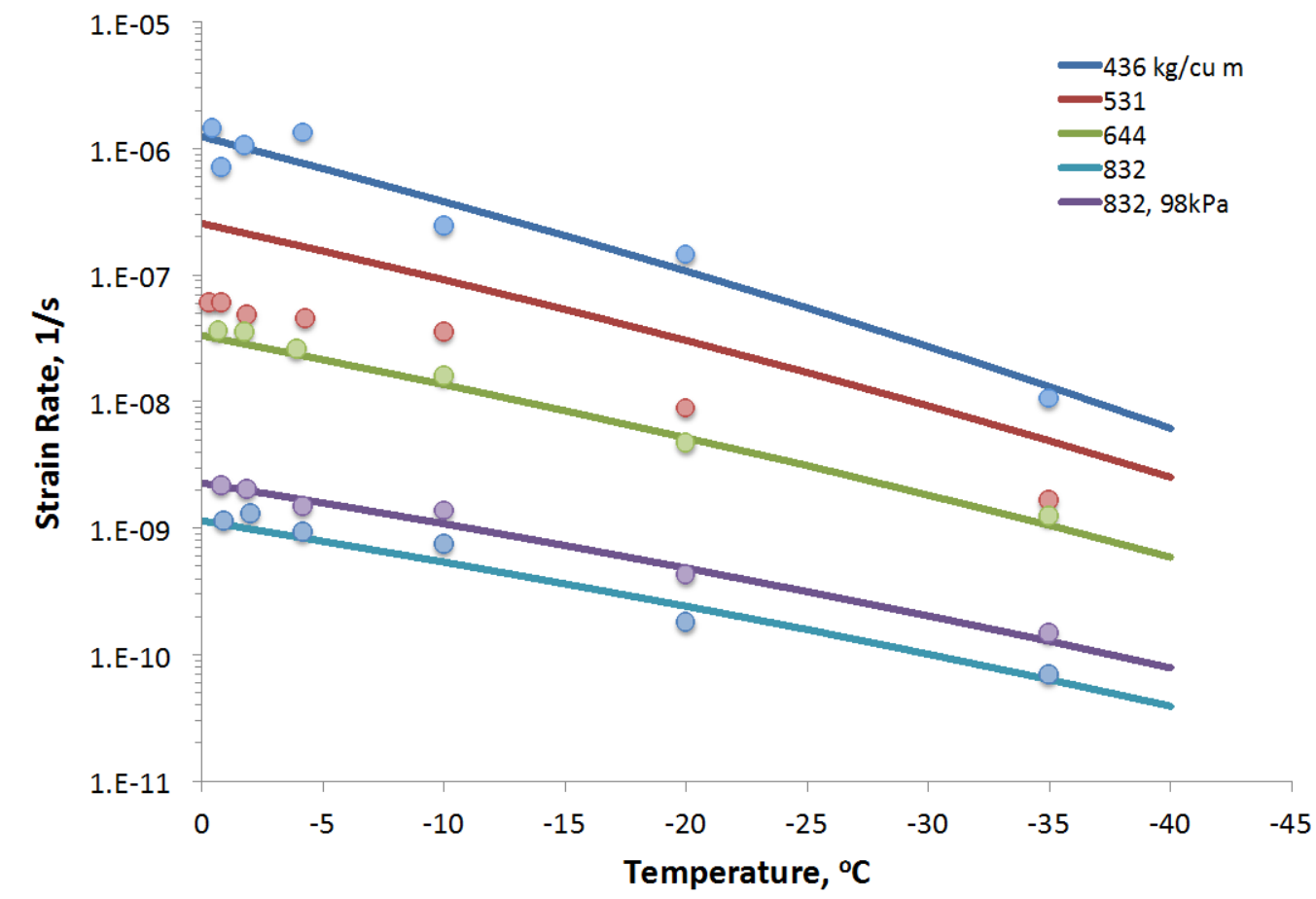

Therefore, I corrected this by adjusting the values of K and Q for the case $\rho$ $=531 \mathrm{~kg} / \mathrm{m}^{3}$ to improve the fit through the remaining points. This greatly improved the model's ability to reproduce all of the cases given in Figure 3, except for $\rho=531 \mathrm{~kg} / \mathrm{m}^{3}$. The resulting model is

$$
\dot{\bar{\varepsilon}}=K C_{T} \sigma ; K\left(\mathrm{~s}^{-1} \mathrm{~Pa}^{-1}\right)=3.32 \times 10^{77} \rho^{-28.3} ; \rho\left(\mathrm{kg} / \mathrm{m}^{3}\right),
$$

which is very similar to Equation (3), with $p=0$, which removes the time dependence on strain rate as is characteristic of secondary creep. Figure 4 compares the model results to the data for snow temperatures of $-1^{\circ} \mathrm{C}$ to $-35^{\circ} \mathrm{C}$. The model was run for 8 cases $(\rho=436,500,531,600,644,700$, 800 , and $832 \mathrm{~kg} / \mathrm{m}^{3}$ ) and an applied stress of $49 \mathrm{kPa}$. Figure 4 shows a smoothly varying model result.

In developing Equation (7), I assumed that the model should be a smoothly varying function over the density range. This was in contrast to the data presented in Figure 3 that show a large drop in the strain rate associated with a change in density of about $100 \mathrm{~kg} / \mathrm{m}^{3}$ between $\rho=436$ and $531 \mathrm{~kg} / \mathrm{m}^{3}$ and a very small drop in strain rate for a similar magnitude density change from 531 to $644 \mathrm{~kg} / \mathrm{m}^{3}$. Figure 4 also shows how the data 
for $\rho=531 \mathrm{~kg} / \mathrm{m}^{3}$ departs from the overall trend in the data. This indicates either that there was a particular problem with the data obtained by Mellor and Smith (1966) associated with $\rho=531 \mathrm{~kg} / \mathrm{m}^{3}$ (e.g., the grain structure of the synthesized snow particles were inconsistent with the other samples) or that there is an abrupt change in the response of snow in the range of 436 and $531 \mathrm{~kg} / \mathrm{m}^{3}$. The current form of the model does not capture that change if the latter is true.

Figure 4. Comparison of data of secondary creep from Mellor and Smith (1966) (symbols) to Equation (7) (line) for the snow temperatures indicated and applied stress of $49 \mathrm{kPa}$. Note that for the temperature of $-20^{\circ} \mathrm{C}$, the ABAQUS constitutive model that follows was applied to a single element model and that the results between the finite element model and Equation (7) are indistinguishable. For all other lines in this figure except $-20^{\circ} \mathrm{C}$, only the model (Equation [7]) results are presented.

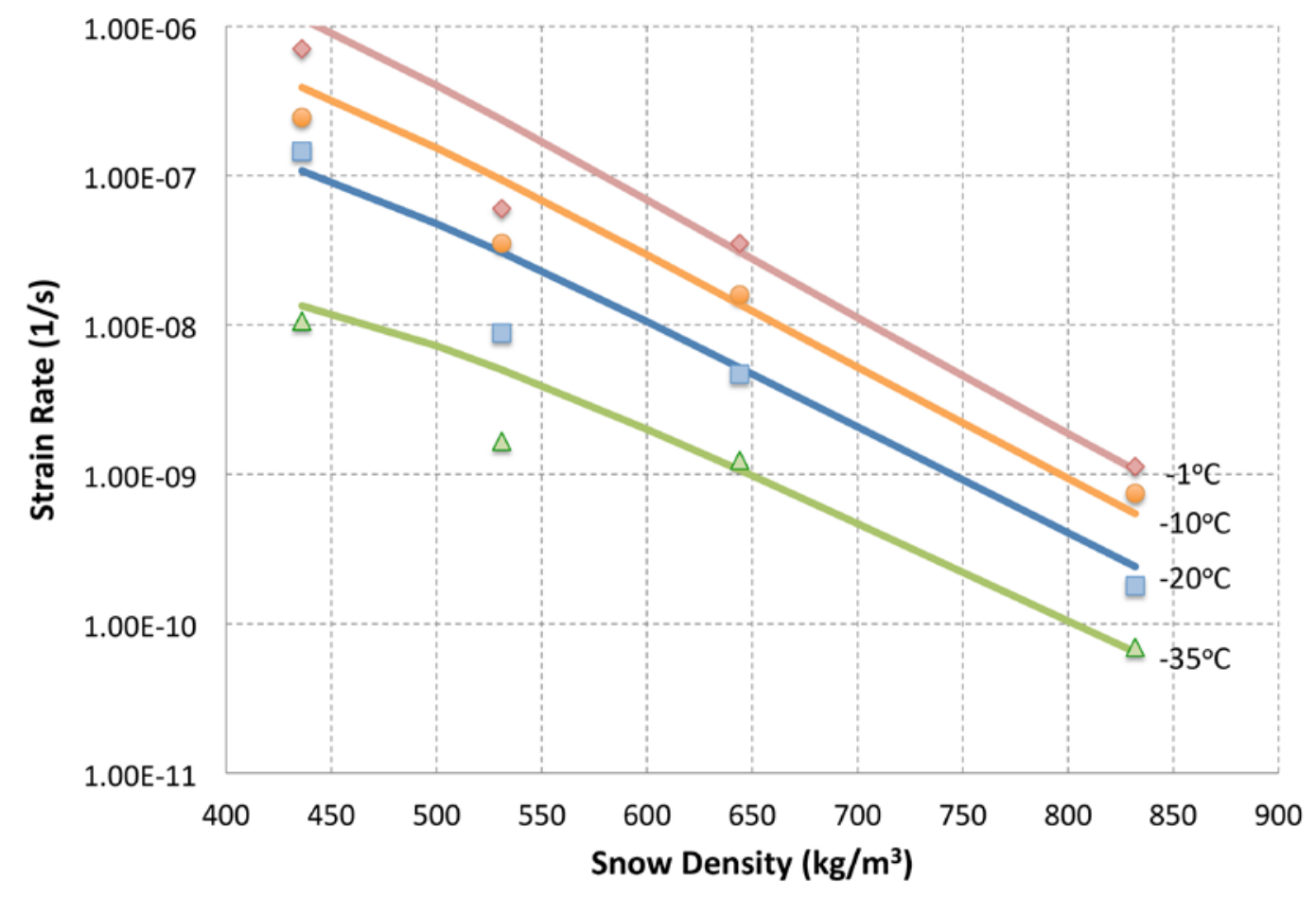




\section{Implementation in ABAQUS}

ABAQUS finite element software provides several creep models for simulating the time-dependent response of materials. The time-dependent law (ABAQUS syntax: *CREEP， LAW=TIME) model has the creep power law form (ABAQUS 2003)

$$
\dot{\bar{\varepsilon}}=A \sigma^{q} t^{p}
$$

where t is time, $\mathrm{A}$ is a parameter similar to $\mathrm{C}$ used in Equation (7), and $\mathrm{q}$ and $p$ determine the power law response for stress and time. Equation (4) and Equation (7) are essentially in this form with $q=1$ for both primary and secondary creep and $p=-0.5$ for primary creep while $p=0$ for secondary creep. $\mathrm{A}=\mathrm{f}(\mathrm{T}, \rho)$ for both, though the factors $\mathrm{C}_{\rho}$ and $\mathrm{K}$ differ for primary and secondary creep.

In addition to the creep response of the material, the elastic properties also need to be specified. Shapiro et al. (1977) provided a compilation of published material properties of snow. They showed that the elastic modulus, $Y$, varies mainly with snow density, though there is considerable scatter in the data. One would expect that there might be temperature dependence, also, though that is not readily apparent; if such dependence exists, it is obscured in the scatter of the published results and may explain the fact that temperature was not plotted as an additional parameter. From these data, I extracted the trend in Y vs. $\rho$ and provide this as a look-up table in ABAQUS (Table 2).

Table 2. Dependency of the elastic modulus on snow density extracted from data compiled in Shapiro et al. (1997). The data extracted follows more closely the data reported by Shapiro et al. (1997) that was acquired from low-strain-rate measurements, more closely akin to the foundation loading considered for the application of this model.

\begin{tabular}{|c|c|}
\hline Snow density, $\mathrm{kg} / \mathrm{m3}$ & Elastic modulus, MPa \\
\hline 200 & 1.379 \\
\hline 380 & 98.20 \\
\hline 410 & 146.9 \\
\hline 470 & 303.3 \\
\hline 540 & 633.6 \\
\hline 620 & 1319.0 \\
\hline 770 & 4165.0 \\
\hline 900 & 9532.0 \\
\hline
\end{tabular}


Shapiro et al. (1997) also compiled the available data for Poisson's ratio, $v$, as a function of snow density. The range in $v$ for snow density from 250 to $850 \mathrm{~kg} / \mathrm{m}^{3}$ is $0.2-0.4$ with no clear trend with density. Therefore, I selected a constant value of $v=0.3$ for these simulations, which is roughly the mean in the data.

\subsection{Primary creep}

This is determined by applying Equation (8) with $\mathrm{q}=1, \mathrm{p}=-0.5$, and $A=$ $C_{\rho} C_{T}$, which can be specified as a function of temperature for a specified snow density. Below is an example of the material model properties for snow with a density of $550 \mathrm{~kg} / \mathrm{m}^{3}$ and a temperature of $-30^{\circ} \mathrm{C}$. This has been implemented as parametric input in ABAQUS so that the values of $\mathrm{A}$ and Young's Modulus are computed automatically when provided the snow density and temperature.

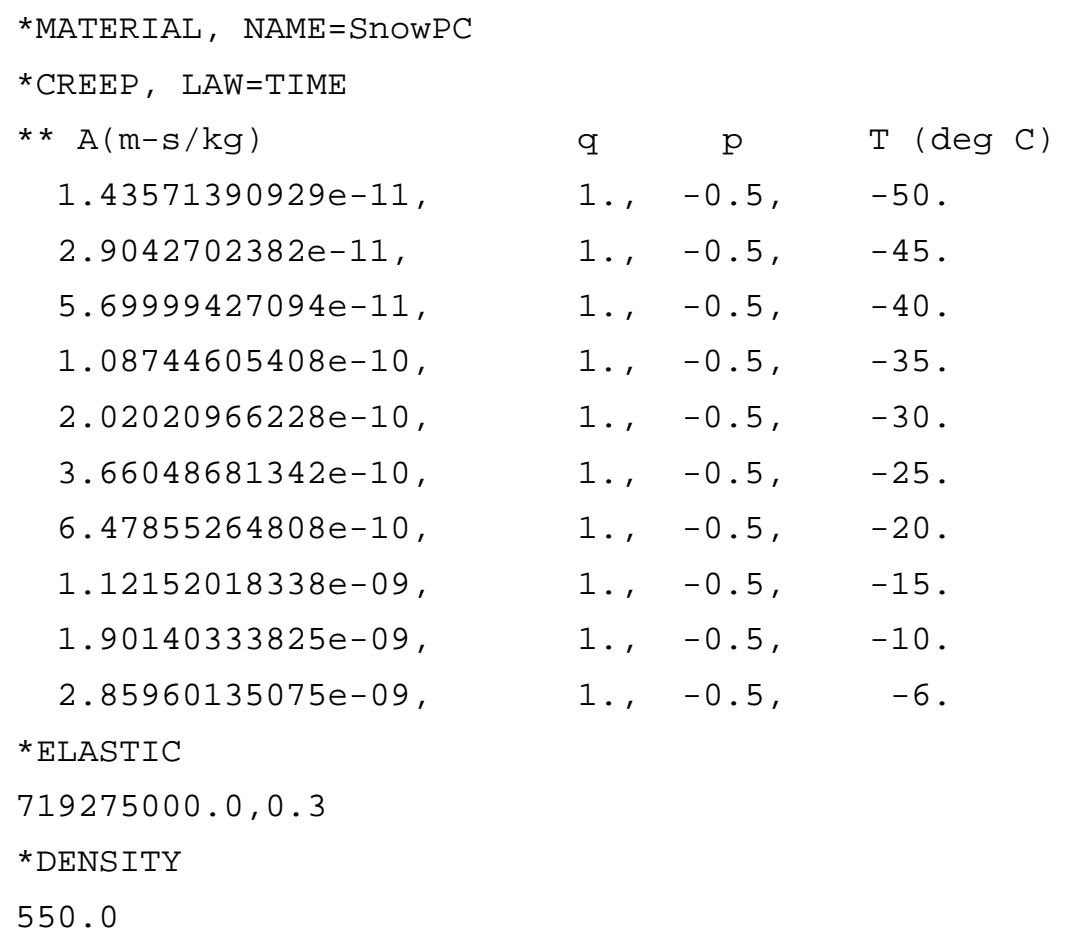

The above model was applied in a single element model with a static load applied to the top of the element as a fixed mass. Therefore, gravity ( $\mathrm{g}=$ $-9.8066 \mathrm{~m} / \mathrm{s}^{2}$ ) acting on the mass provided the axial stress on the sample and replicated static creep loading. Initially, the load was applied using a *STATIC step with an amplitude ramp so that the acceleration of gravity increased from 0 to $g$ in $1 \mathrm{~s}$. This allowed the sample to deflect elastically. 
The load was held constant during the next step ( ${ }^{*}$ VIsco) to allow the sample to deform viscoelastically in creep. The duration of this step was $1000 \mathrm{~s}$. The deformation rate during this second load step was used to compute the strain rate.

This study ran four cases to demonstrate the primary creep model. The first was a comparison to a measured data set obtained by Meussen et al. (1999) and presented in Figure 5; the agreement with this test case is very good. The next section, "Comparison of Primary and Secondary Creep Models," discusses the other three cases.

Figure 5. Implemented in ABAQUS, a comparison of model results (Equation [3]) to the creep behavior of snow observed by Meussen et al. (1999). The simulated and measured data are for a snow temperature of $-20^{\circ} \mathrm{C}$ and a density of $450 \mathrm{~kg} / \mathrm{m}^{3}$. The applied load is $220 \mathrm{kPa}$.

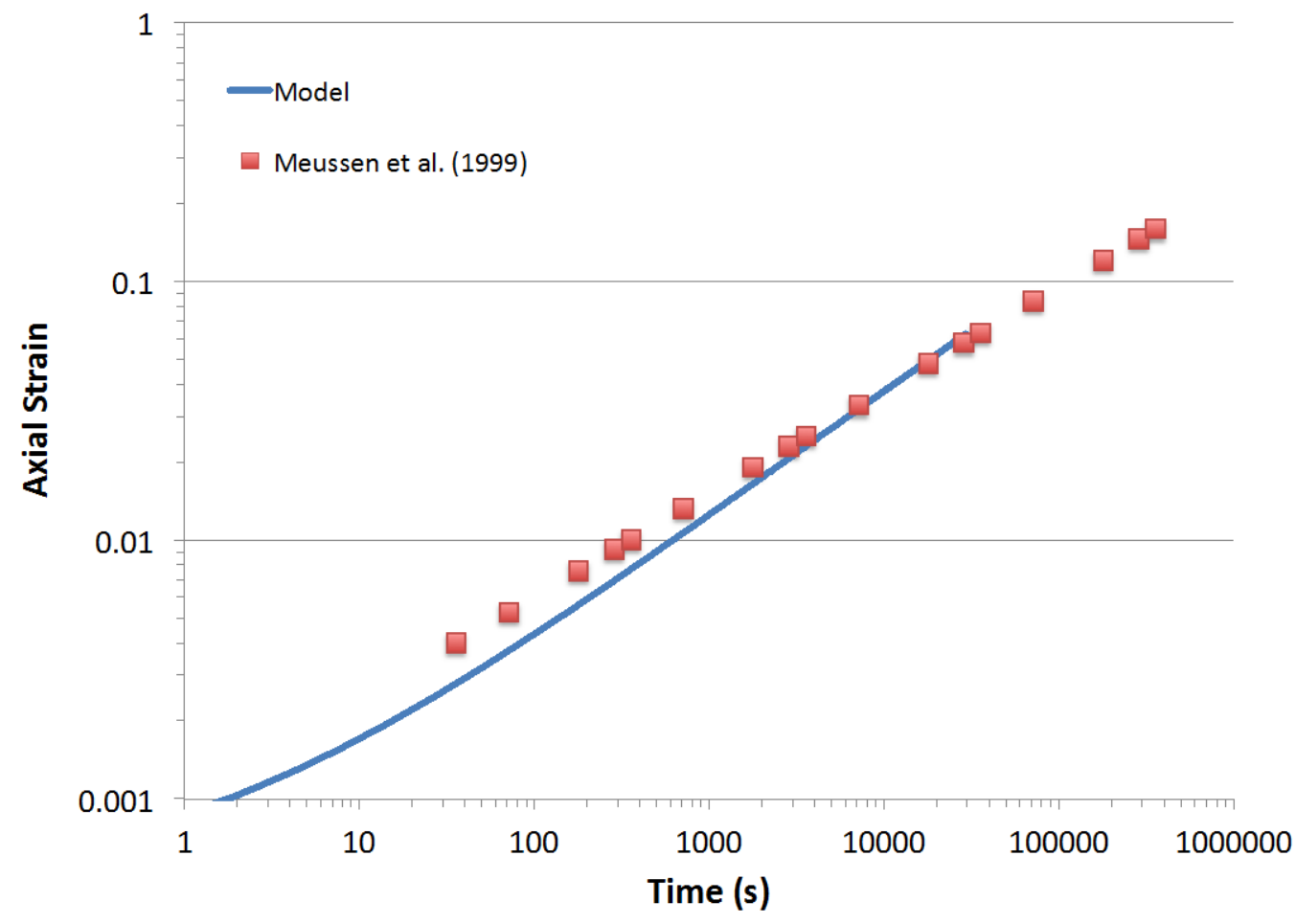

\subsection{Secondary creep}

For this case, I used in Equation (8) $\mathrm{q}=1, \mathrm{p}=0$, and $A=K C_{T}$. In ABAQUS, A can be specified as a function of temperature for a specified snow density.

Using the above information, the material specification in ABAQUS for snow at $-20^{\circ} \mathrm{C}$ and a density of $436 \mathrm{~kg} / \mathrm{m}^{3}$ is as follows: 


\begin{tabular}{|c|c|c|c|}
\hline ** $A(m-s / k g)$ & $q$ & $\mathrm{p}$ & $T(\operatorname{deg} C)$ \\
\hline $2.47086400868 \mathrm{e}-14$ & 1. & ๑. , & -50 \\
\hline $5.66466039457 e-14$ & 1. & ๑. , & -45 \\
\hline $1.25324020658 \mathrm{e}-13$, & 1. & ๑. , & -40 \\
\hline $2.68166686721 e-13$ & 1. , & $\odot .$, & -35 \\
\hline $5.56134501594 \mathrm{e}-13$ & 1. , & ๑. , & -30. \\
\hline 1.11990624221e-12, & 1. , & ๑. , & -25 \\
\hline $2.19365137898 \mathrm{e}-12$ & 1. , & ๑. , & -20 \\
\hline $4.18635707718 \mathrm{e}-12$ & 1. , & ๑., & -15 \\
\hline 7. $79530507393 e-12$, & 1. , & ๑. , & -10 \\
\hline 1. $41825869341 \mathrm{e}-11$, & 1. , & ๑., & -5 \\
\hline $2.25326892625 e-11$ & 1. & ๑., & -1 \\
\hline \multicolumn{4}{|l|}{${ }^{\star}$ ELASTIC } \\
\hline \multicolumn{4}{|l|}{$214673333.333,0.3$} \\
\hline *DENSITY & & & \\
\hline 36.0 & & & \\
\hline
\end{tabular}

This was applied in the same single element model described above and was used for validation of the primary creep model, which replicated the loads imposed by Mellor and Smith (1966). The finite element model result was compared against the data from Mellor and Smith (1966) at $-20^{\circ} \mathrm{C}$, and it exactly reproduced the model (Equation [7]) shown in Figure 4 .

\subsection{Including variation of density with depth}

To include the variation of density with depth, I added an additional field variable to the material models shown previously: depth. This was implemented with a user-defined-field subroutine in ABAQUS (USDFLD . $f$-Appendix A provides an example). The uSDFLD . f subroutine used for this effort extracts the depth in the model and applies the properties in a tabular fashion similar to what is shown above for temperature. The variation for density and depth provided for in the table is as follows.

A density vs. depth relationship is required, such as data collected by Albert (unpublished) at Summit, Greenland. Haehnel and Knuth (2011) determined a curve fit to the Albert (unpublished) data: 


$$
\begin{aligned}
& \rho\left(\frac{\mathrm{kg}}{\mathrm{m}^{3}}\right)=323+68.26 d^{0.45} ; 0 \leq \mathrm{d} \leq 120 \mathrm{~m} \\
& \rho\left(\frac{\mathrm{kg}}{\mathrm{m}^{3}}\right)=912 ; \mathrm{d}>120 \mathrm{~m}
\end{aligned}
$$

For the ABAQUS material model, I formulate a linear interpolation of density variation with depth for three depths, $\mathrm{z}=\mathrm{f}$ (surface density), $20 \mathrm{~m}$, and $120 \mathrm{~m}$. Though this may seem coarse, it does an adequate job of following the depth- density trend over the region of interest ( $\sim 3 \mathrm{~m}$ to $50 \mathrm{~m}$ ) as demonstrated in Figure 6. Note that the starting depth is not $\mathrm{z}=0 \mathrm{~m}$ because the foundation will be set on a snow surface that is below the natural grade (i.e., the top surface will be excavated down to some depth, e.g., $3 \mathrm{~m}$ ) and the foundation will be set on that surface. Note that if the ABAQUS model required a better definition in the density- depth relation, one could increase the number of depths in the input table for ABAQUS.

Figure 6. Comparison of depth vs. density at Summit Station, Greenland (solid line), and linear approximation using 3 points.

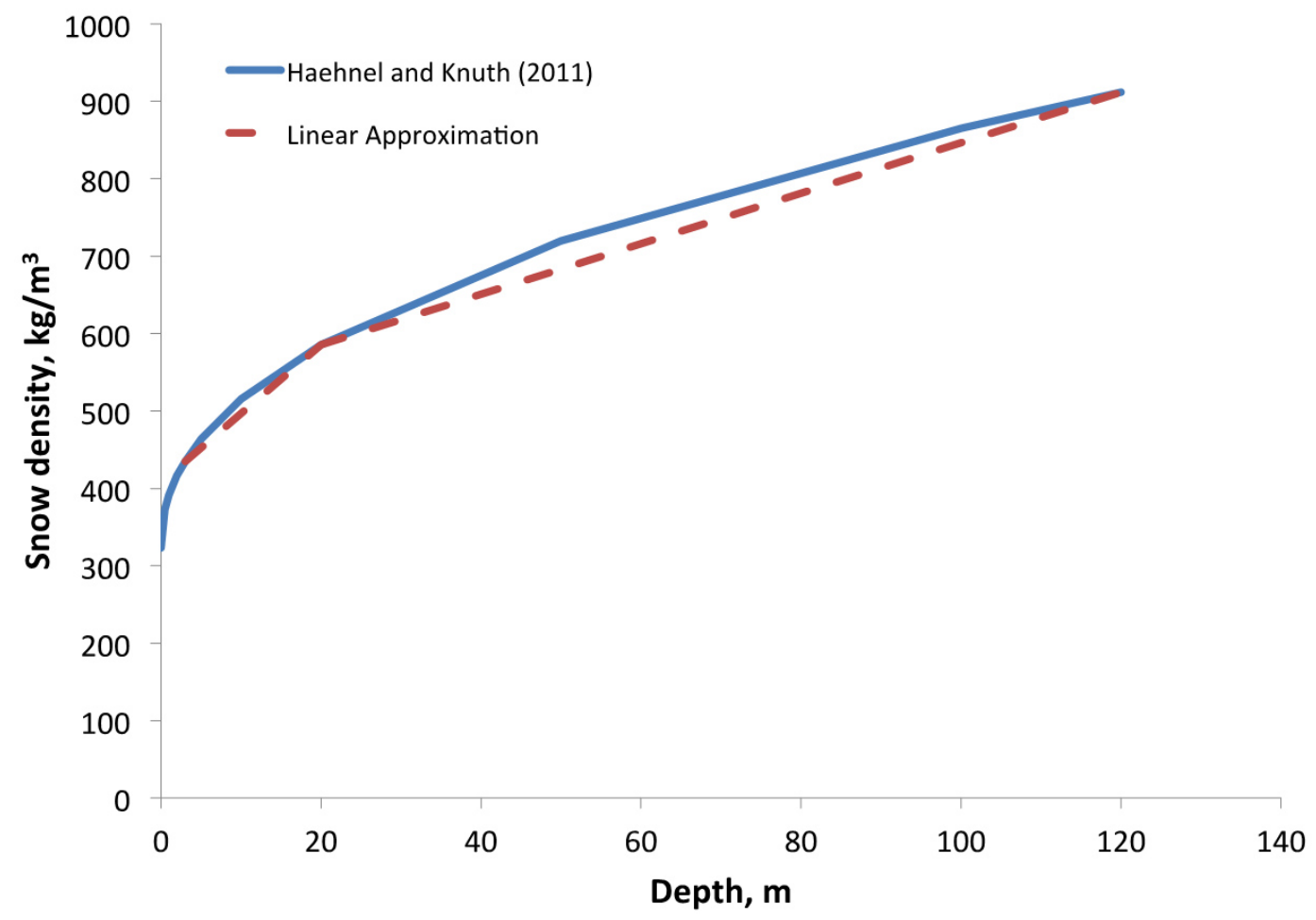


The material model for secondary creep that varies with depth is then as follows:

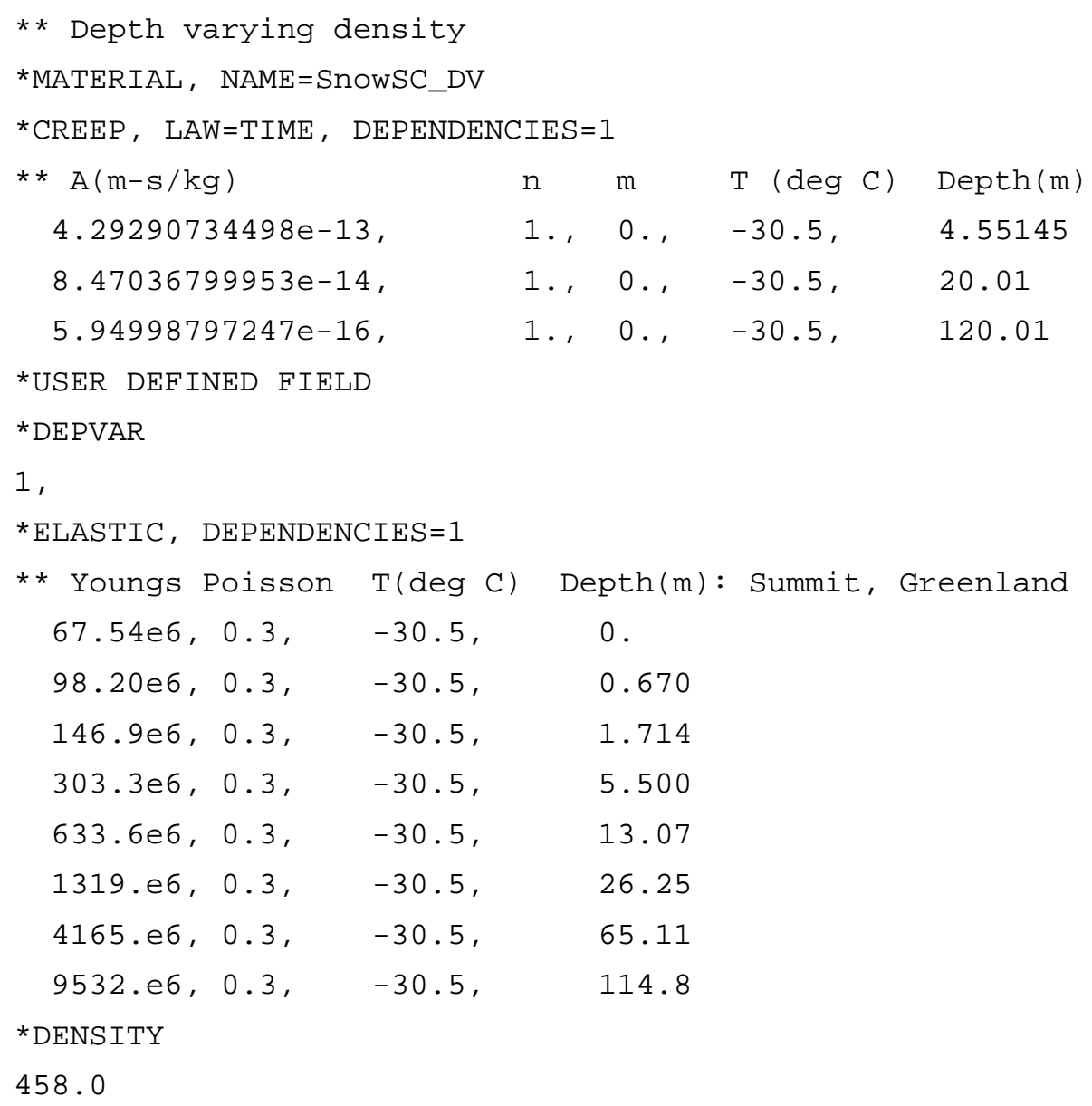

The material model for primary creep is not shown here but is formulated similarly. 


\section{Comparison of Primary and Secondary Creep Models}

To verify that the primary and secondary creep models behaved as expected, I conducted finite element simulations of axial compression on a radially unconfined snow sample by using Equation (4) (primary creep) and Equation (7) (secondary creep). For the primary creep model, I also explored the response of the snow with temperature. Figure 7 provides the results of these simulations.

Figure 7 shows that the axial strain decreases with temperature as would be expected and thus demonstrates that the primary creep model presented in Equation (4) behaves appropriately. Second, I compared the axial strain that the secondary creep model (Equation [7]) would predict over the same elapsed time. For this comparison, I used a constant snow temperature of $-30^{\circ} \mathrm{C}$ (the red solid and dashed lines in Figure 7).

Figure 7. Comparison of axial strain predicted using Equation (3) (primary creep) as a function of snow temperature. For comparison, the figure also shows the axial strain predicted for the secondary creep relationship (dashed line) (Equation [6]). The snow density for all of these simulations is $550 \mathrm{~kg} / \mathrm{m}^{3}$. The applied stress is $15 \mathrm{kPa}$.

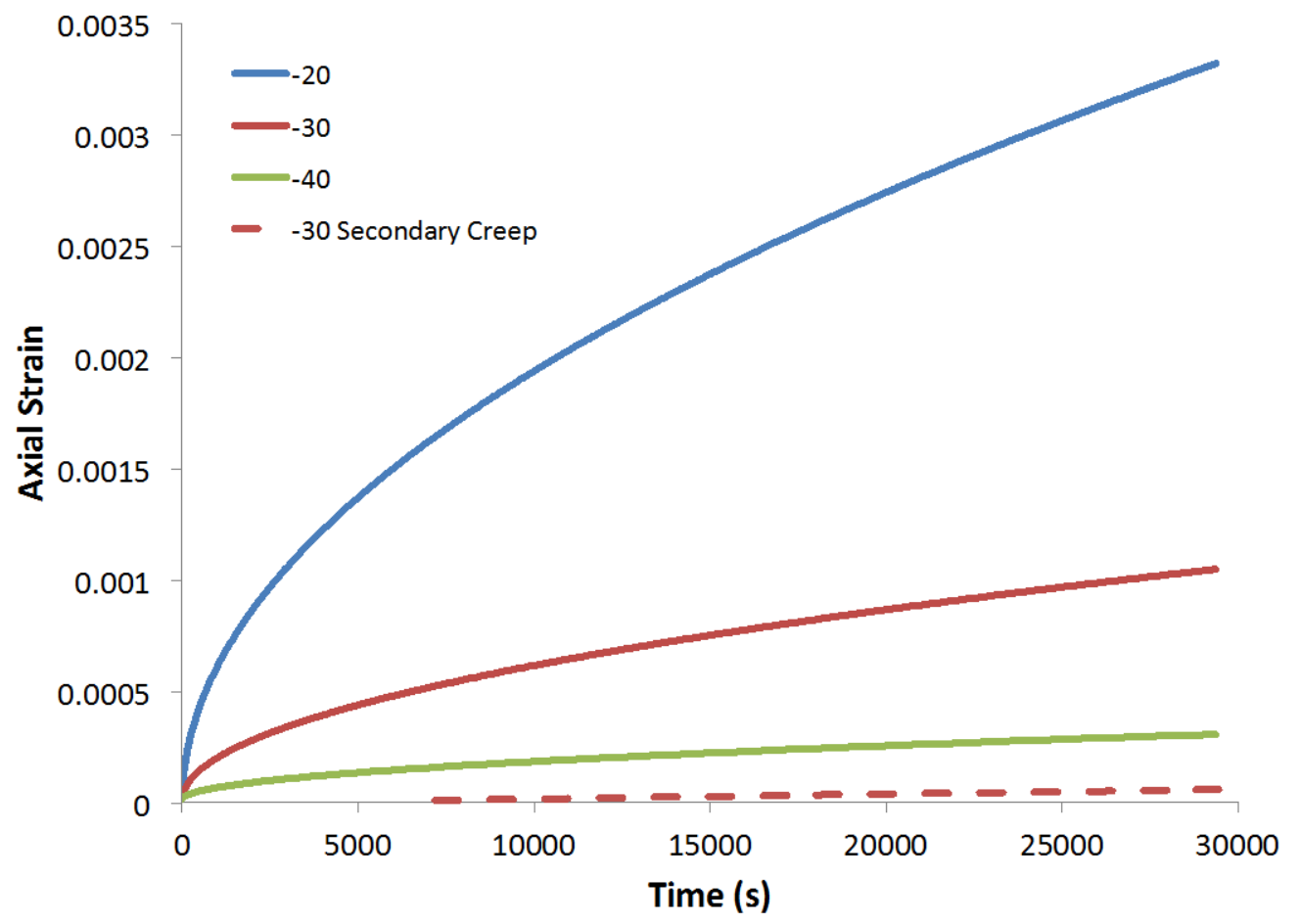


Clearly, the axial strain during secondary creep is much smaller than that experienced during primary creep. I note that the time duration of these simulations is a little more than 8 hours (roughly equivalent to a GLT pointing operation). One can observe that the slope of the primary creep curve for $-30^{\circ} \mathrm{C}$ (red solid line) at the end of the simulation (around 8 hours) is still higher than the slope of the secondary creep line, though the primary creep model is clearly trending toward the shallower slope of the secondary creep line. At about 8 hours of simulated time, the strain rate associated with primary creep is about 20 times larger than the strain rate that the snow would experience during the secondary creep regime. When I applied Equation (4) to longer times, I found that for a snow temperature of $-30^{\circ} \mathrm{C}$, it would take about 500 hours (21 days) for the strain rate associated with primary creep to decline to the same level as that seen for secondary creep (Equation [7]) of snow at the same temperature. Note that the time to transition from primary to secondary creep for these simulations is not universal but is highly dependent on the load configuration. For a uniaxial compression test geometry (results in Figure 6), the model predicts the time to transition from primary to secondary creep response is about 21 days. For a radially confined case (e.g., a building placed on a semi-infinite snow foundation), the time to transition from primary to secondary creep is likely longer. 


\section{Model Validation Against Field Data}

The model validation discussed in previous sections compares the model results to uniaxial compression tests performed in the laboratory. I now show results for the secondary creep model compared to field measurements made by Reed (1966) wherein a wooden raft is loaded with a weight and placed on the snow surface of the Greenland ice sheet at Camp Century. The settling of the raft was monitored over the course of about 2 years. Secondary creep was the dominant deformation mechanism during these experiments. Therefore, I use the depth-varying secondary creep model (i.e., SnowSC_DV in Section 4.3) in these simulations. The density of the snow surface on which the rafts were placed was about $458 \mathrm{~kg} / \mathrm{m}^{3}$ (Reed 1974) on a surface that was at least $0.46 \mathrm{~m}$ below the original snow surface. Reed (1966) studied several rafts of varying geometry and loadings. I consider only the tests conducted by Reed (1966) that used square rafts ranging from 0.4572 to $1.372 \mathrm{~m}$ on a side and loaded at $47.8 \mathrm{kPa}$. Reed (1966) reported that the average snow temperature was $-20^{\circ} \mathrm{C}$; the temperature at the $3 \mathrm{~m}$ depth varied from $-17^{\circ} \mathrm{C}$ to $-24^{\circ} \mathrm{C}$ throughout the test period (approximately 700 days).

At Camp Century, the density vs. depth relationship is different from that at Summit. Benson (1962) provided some data on how density varies with depth in the region near Camp Century. I extracted the data from Figure 52 in that work. A reasonable fit to the data is

$$
\rho\left(\frac{\mathrm{kg}}{\mathrm{m}^{3}}\right)=355.8+60.17 d^{0.474} ; 0 \leq \mathrm{d} \leq 100 \mathrm{~m} .
$$

Note that this is only applicable down to a $100 \mathrm{~m}$ depth. Beyond about $100 \mathrm{~m}$, the change in density with depth progresses more slowly as it approaches the density of solid ice. Yet Equation (10) provides sufficient information for this validation effort as the model depth is only to about $14 \mathrm{~m}$.

Also of note, the observations of Benson (1962) indicated that at depths below 3.2 to $4 \mathrm{~m}$, the temperature is fairly uniform, at about $-25^{\circ} \mathrm{C}$, down to at least 8- 9 m; so, though Reed (1966) observed a near-surface average snow temperature of $-20^{\circ} \mathrm{C}$, the temperature in the column of snow affected by the surface load is colder and can range down to $-25^{\circ} \mathrm{C}$. For this 
reason, I ran the simulation with several snow temperatures to try to understand the influence of snow temperature on settlement rate and how that compares to Reed's (1974) observations.

Figure 8 plots the settlement rate for the four square rafts loaded at $47.8 \mathrm{kPa}$ reported by Reed (1974) (indicated by the diamonds). The solid line indicates a least-squares linear fit to the data.

Figure 8. Comparison of model results to the data of Reed (1974). This is the same data obtained by Reed (1966) with the settlement rates adjusted to a snow density of $458 \mathrm{~kg} / \mathrm{m}^{3}$.

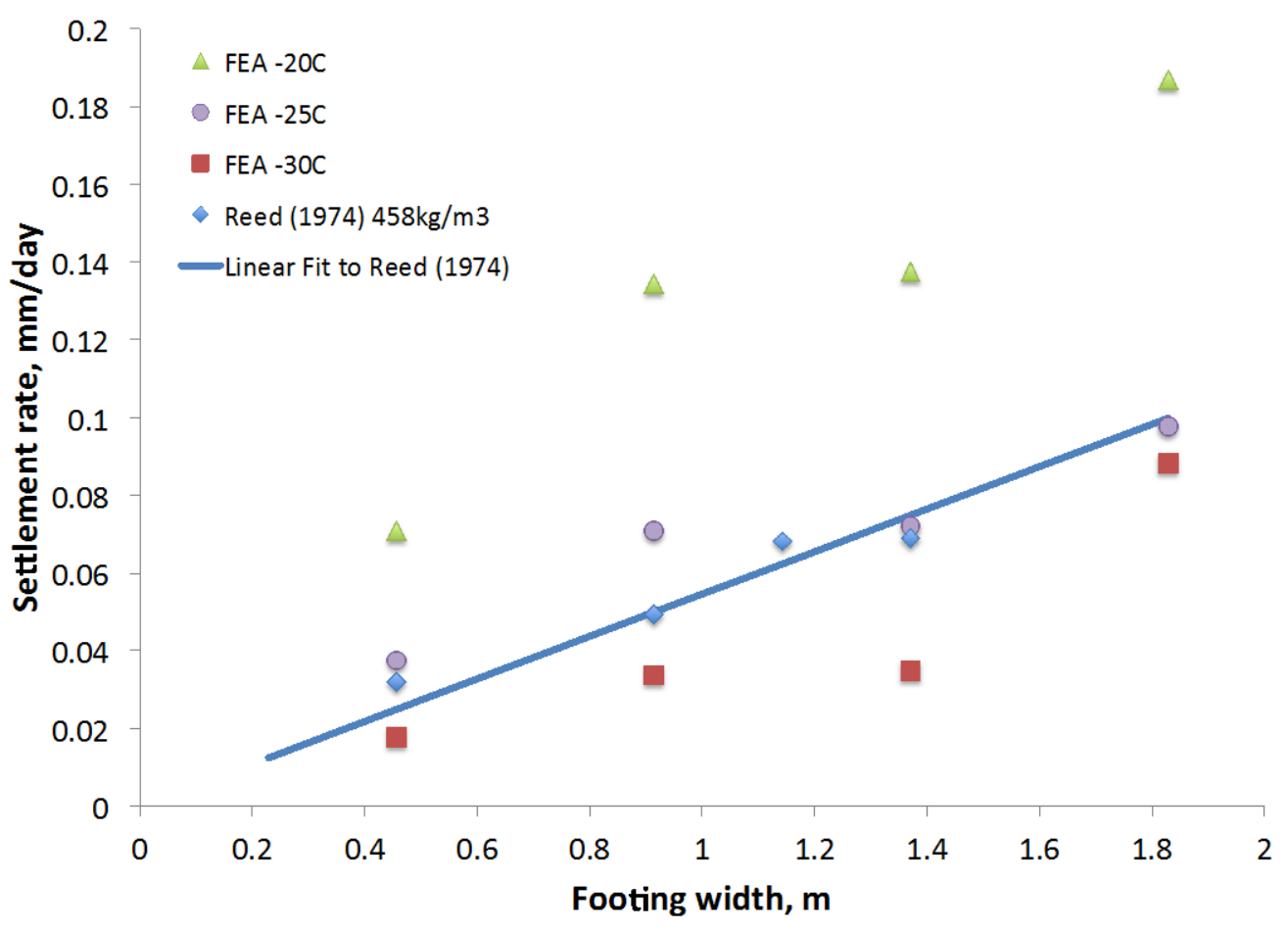

Figure 9 shows the finite element model. Because of symmetry, I used a quarter space of the simulated geometry. The snow is modeled as a quarter cylinder, and one-quarter of the square raft is loading the model at the corner of the sector. The stress bulb in the snow is clearly visible in Figure 9. The radius of the domain is $2.74 \mathrm{~m}$. The outer edge of the domain uses infinite elements to project the domain in the radial direction. The height of the domain is $13.7 \mathrm{~m}$. This is sufficiently tall that the stress bulb does not effectively see the lower boundary of the domain.

I ran simulations at three snow temperatures $\left(-20^{\circ} \mathrm{C},-25^{\circ} \mathrm{C}\right.$, and $\left.-30^{\circ} \mathrm{C}\right)$ and for raft sizes of $0.457,0.914,1.37$, and $1.83 \mathrm{~m}$. I extended the raft size beyond that used by Reed 1966 to get a feel for how the settlement rate trended as the contact area continued to grow. I also ran an additional case 
to verify the computational mesh shown in Figure 9 was sufficiently fine. This added case had a mesh that was twice as fine as that shown in Figure 9; the snow temperature was $-30^{\circ} \mathrm{C}$, and the raft size was $1.37 \mathrm{~m}$. Comparing these results to the same conditions on the coarser mesh, I found no difference in the computed settlement rate and therefore concluded that the $0.17 \mathrm{~m}$ mesh shown in Figure 9 was sufficiently fine and subsequently ran all of the cases at that resolution.

Figure 9. The model domain used for simulating the load cases outlined in Reed (1966). The raft is not shown to allow viewing of the stress state of the snow immediately under the raft. The load case is quarter space for the $1.37 \mathrm{~m}$ raft loaded at $47.8 \mathrm{kPa}$.

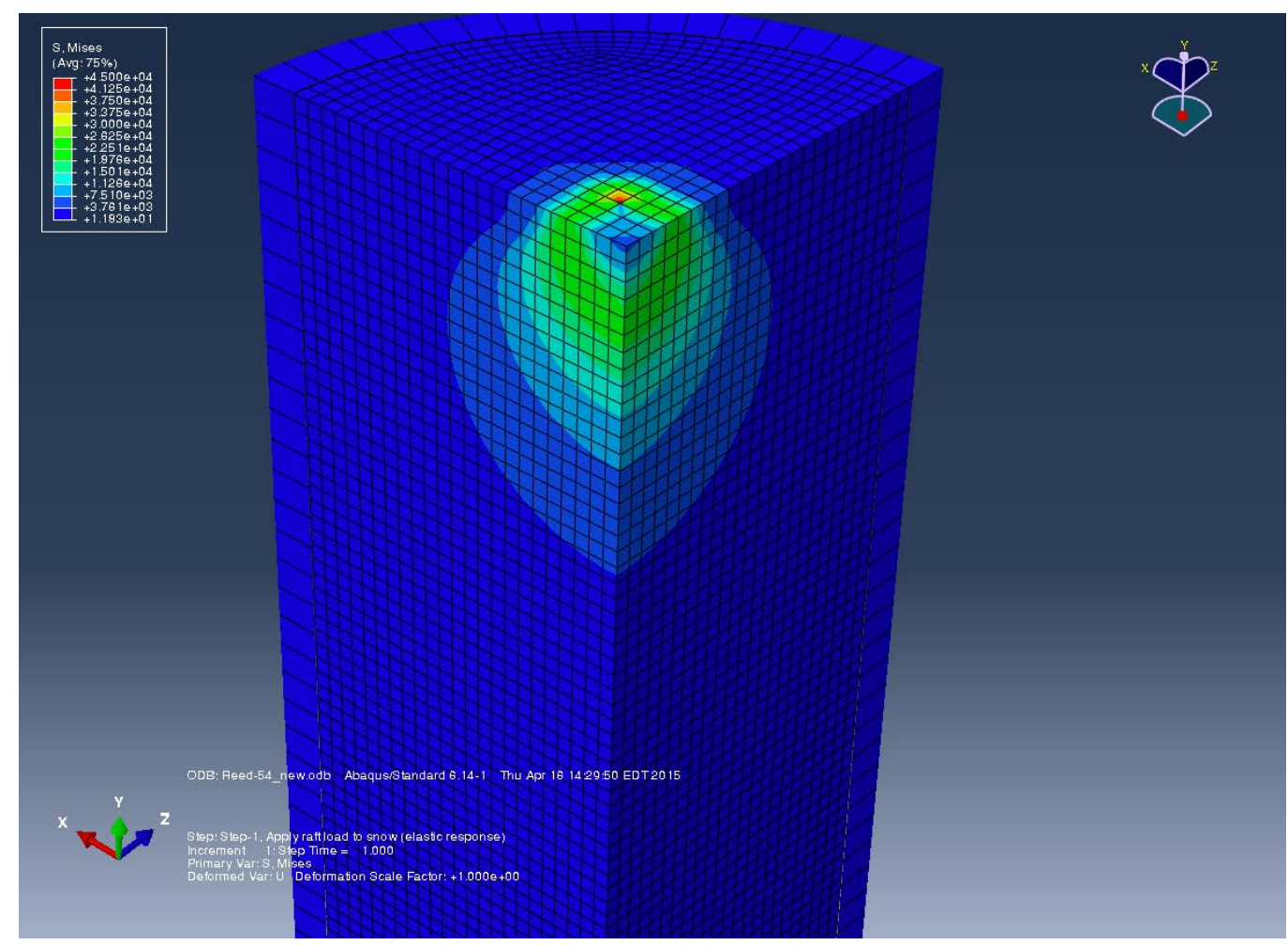

Figure 8 compares the simulated results to Reed's (1966, 1974) data. The agreement between the model with the snow temperature of $-25^{\circ} \mathrm{C}$ and that of the Reed data is remarkably good when considering the uncertainty and spatial and temporal variability of the snow temperature in the field case. The model also faithfully reproduces the field observation that the increasing footing area, with constant pressure at the base of the footing, increases the settlement rate; the total load on the footing is increased, leading to a higher settlement rate even though the pressure under the footing is constant. 


\section{Conclusions and Recommendations}

I determined parameters and empirical expressions to allow use of the ABAQUS creep constitutive law (a creep power law, Equation [8]) to model the primary and secondary creep response of a dense snow ( $\rho=440$ - $890 \mathrm{~kg} / \mathrm{m}^{3}$ ). Owing to the lack of data that spanned from the primary to secondary creep response of the snow, I developed two separate models from the available data, one for primary creep (Equation [4]) and another for secondary creep (Equation [7]).

Prior efforts to model primary and secondary creep in snow resulted in models that differ from the creep power law used in ABAQUS. In this effort, I reformulated the models used by others to determine creep power law parameters that could be used in the standard ABAQUS creep model.

Comparing model-predicted strain and settlement to published data shows that the secondary creep model effectively reproduces the limited available laboratory and field observations of creep deformation of dense snow. This study could perform only a limited validation of the primary creep model because of limited data documenting the primary creep response of snow. However, Figure 7 compares the relative magnitude of strain to expect during primary and secondary creep phases. These results follow expectations, even if Equation (4) cannot be fully validated at present.

The models developed here (primary creep, Equation [4], and secondary creep, Equation [7]) are useful in illustrating the relative deformation that can occur during the two creep regimes. However, it is difficult to simulate long-term behavior that captures the transition from primary to secondary creep response of the snow by having them as two separate models. I recommend a follow up effort to merge these two models into a single (e.g., Maxwell-Voigt) model that describes the creep response of snow from initial load application through primary creep phase and the transition to secondary creep deformation. Development of a more generalized snow creep model will require considerably more effort than that expended to determine the parameters for the piecewise models developed for this study. 
A separate but parallel work applied the models developed in this effort to estimate the differential foundation settlement of the proposed GLT during an 8-hour pointing operation. 


\section{References}

ABAQUS. 2003. Analysis User's Manual Volume III: Materials. Pawtucket, RI: ABAQUS Inc.

Albert, M. Unpublished data. Polar Snow and Firn Properties, Summit Station, Greenland. Hanover, NH: U.S. Army Engineer Research and Development Center.

Benson, C. S. 1962. Stratigraphic Studies in the Snow and Firn of the Greenland Ice Sheet. Research Report 70. Wilmette, IL: U.S. Army Snow, Ice, and Permafrost Research Establishment.

Chandel, C., P. K. Srivastava, and A. Upadhyay. 2007. Estimation of Rheological Properties of Snow Subjected to Creep. Defence Science J ournal 57 (4): 393- 401.

Glen, J. W. 1955. The Creep of Polycrystalline Ice. In Proceedings of the Royal Society of London Series A 288 (1175): 519- 38.

Haehnel, R., and M. Knuth. 2011. Potable Water Supply Feasibility Study for Summit Station, Greenland. ERDC/ CRREL TR-11-4. Hanover, NH: U.S. Army Engineer Research and Development Center.

Kovacs, A. 1967. Feasibility Study of Buried Anchors in Polar Snow. Special Report 107. Hanover, NH: Cold Regions Research and Engineering Laboratory.

Mellor, M. 1969. Foundations and Subsurface Structures in Snow. Monograph III-A2c. Hanover, NH: Cold Regions Research and Engineering Laboratory.

Mellor, M., and J . H. Smith. 1966. Creep of Snow and Ice. Research Report 220. Hanover, NH: Cold Regions Research and Engineering Laboratory.

Meussen, B., O. Mahrenholtz, and H. Oerter. 1999. Creep of Polar Firn. Cold Regions Science and Technology 29 (3): 177- 200.

Reed, S. C. 1966. Spread Footing Foundations on Snow. Technical Report 175. Hanover, $\mathrm{NH}$ : Cold Regions Research and Engineering Laboratory.

— 1974. Design of Footing Foundations on Polar Snow. Technical Report 219. Hanover, NH: Cold Regions Research and Engineering Laboratory.

Shapiro, L. H., J . B. Johnson, M. Sturm, and G. B. Blaisdell. 1997. Snow Mechanics: Review of the State of Knowledge and Applications. CRREL Report 97-3. Hanover, $\mathrm{NH}$ : Cold Regions Research and Engineering Laboratory. 


\section{Appendix A: Density vs. Depth Material Model}

The subroutine USDFLD. $f$ is given below. Note that it is set up such that the vertical direction (elevation or depth) is associated with the y-axis: coord (2) as is used in the ABAQUS model for which it is paired with. The variable elev is the elevation in the model that represents the top of the snow surface. The below code specifies elev $=0$, that is, the model is set up such that the top of the snow surface is at $Y=0$. This may not be the case in all models and will need to be adjusted accordingly in this subroutine to address individual simulations. Also, the starting density of the snow (snow density at the surface) needs to be entered in for the variable rho. If the model is placed on the surface of the snow and is not excavated down to a particular depth before the foundation is placed, then this is the surface density of the snow. Otherwise, it is the density at the depth of the excavation. In the case below, rho $=458$ (units of $\mathrm{kg} / \mathrm{m}^{3}$ ). The subroutine then computes the density-adjusted depth, ddepth, by using the appropriate density vs. depth relationship. In this case, I use the density vs. depth relationship for Summit Station, Greenland, given in Haehnel and Knuth (2011). If a different relationship is appropriate, it needs to be entered into the subroutine here, replacing the existing expression.

\section{USDFLD.f:}

SUBROUTINE USDFLD(FIELD, STATEV, PNEWDT, DIRECT, T, CELENT, +TIME, DTIME, CMNAME, ORNAME, NFIELD, NSTATV, NOEL, NPT, LAYER, +KSPT , KSTEP, KINC, NDI , NSHR, COORD, JMAC, JMATYP, MATLAYO, +LACCFLA)

C

INCLUDE 'ABA_PARAM.INC'

C

CHARACTER * 80 CMNAME, ORNAME

CHARACTER * 3 FLGRAY (15)

DIMENSION FIELD(NFIELD), STATEV(NSTATV), DIRECT $(3,3)$,

$+\mathrm{T}(3,3), \operatorname{TIME}(2)$

$\operatorname{DiMENSION~ARRAY}(15), \operatorname{JARRAY}(15), \operatorname{JMAC}\left({ }^{*}\right), \operatorname{JMATYP}\left({ }^{*}\right)$,

$+\operatorname{COORD}\left({ }^{*}\right)$

real z, elev, ddepth, rho

c snow density 
rho $=458$.

c elevation in model of top of snow surface

$c$ this needs to be set according to the model geometry elev $=\odot$.

c density depth $d=([$ rho-323]/68.26)** $(1 / 0.45)$ for Summit, Greenland

ddepth $=((\text { rho-323. }) / 68.26)^{* *}(1 / 0.45)$

c model set up such that $Y$ is the vertical direction $z=\operatorname{coor} d(2)$

c field to pass back to ABAQUS FIELD $(1)=$ ddepth + elev $-z$

RETURN

END 


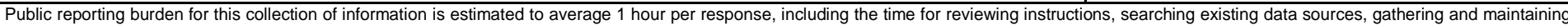

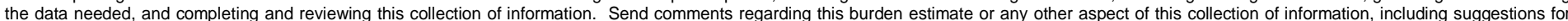

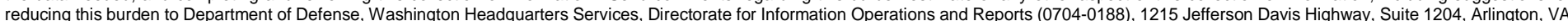

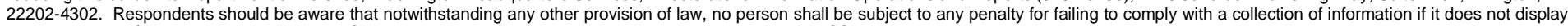
a currently valid OMB control number. PLEASE DO NOT RETURN YOUR FORM TO THE ABOVE ADDRESS.
1. REPORT DATE (DD-MM-YYYY) 2. REPORT TYPE
April 2017
Technical Report/Final

3. DATES COVERED (From - To)

\section{TITLE AND SUBTITLE}

A Creep Model for High-Density Snow

5a. CONTRACT NUMBER

5b. GRANT NUMBER

5c. PROGRAM ELEMENT NUMBER

6. AUTHOR(S)

Robert B. Haehnel

5d. PROJECT NUMBER

SAO-GLT-16-01

5e. TASK NUMBER

5f. WORK UNIT NUMBER

7. PERFORMING ORGANIZATION NAME(S) AND ADDRESS(ES)

8. PERFORMING ORGANIZATION REPORT NUMBER

U.S. Army Engineer Research and Development Center (ERDC)

Cold Regions Research and Engineering Laboratory (CRREL)

ERDC/CRREL TR-17-7

72 Lyme Road

Hanover, NH 03755-1290

9. SPONSORING I MONITORING AGENCY NAME(S) AND ADDRESS(ES)

10. SPONSOR/MONITOR'S ACRONYM(S)

SAO

Smithsonian Astrophysical Observatory

60 Garden Street

Cambridge, MA 02138

11. SPONSOR/MONITOR'S REPORT NUMBER(S)

\section{DISTRIBUTION I AVAILABILITY STATEMENT}

Approved for public release; distribution is unlimited.

\section{SUPPLEMENTARY NOTES}

\section{ABSTRACT}

This effort modifies Mellor and Smith's creep model for dense snow to conform to the more general creep power law form (Glen's creep law for ice is a special case of this power law). The present study used this general form as the basis for developing two creep models: one to describe the primary creep and another that models secondary creep response as a function of applied stress, snow density, and temperature. Available laboratory data helped to determine the parameters for these models. These models were recast into a form compatible with the ABAQUS finite element software to allow simulation of settlement of a snow foundation subjected to a long-term load.

The secondary creep model was validated against the observed settlement of a spread foundation on snow at Camp Century, Greenland. Though there were not suitable field data to validate the primary creep model, comparison of that model to results obtained for the secondary creep model demonstrate that the primary creep model behaved as expected. Additional work is necessary to merge the primary and secondary creep models and to further validate the primary creep response of the model presented here.

\section{SUBJECT TERMS}

Creep deformation, Finite element method, Foundations--Cold weather conditions, Greenland, Polar construction, Snow, Snow mechanics

16. SECURITY CLASSIFICATION OF:

\section{a. REPORT}

Unclassified

\section{b. ABSTRACT}

Unclassified

\section{c. THIS PAGE}

Unclassified

17. LIMITATION
OF ABSTRACT
SAR

\begin{tabular}{l|} 
18. NUMBER \\
OF PAGES \\
\cline { 2 - 2 } \\
\cline { 2 - 2 }
\end{tabular}

19a. NAME OF RESPONSIBLE PERSON

19b. TELEPHONE NUMBER (include area code) 